\title{
The development of ethical guidelines for telemedicine in South Africa
}

\author{
B A Townsend, ${ }^{1} \mathrm{PhD} ; \mathbf{R}$ E Scott, ${ }^{1,2} \mathrm{PhD}, \mathrm{BSc}$ Hons; M Mars, ${ }^{1} \mathrm{MB} \mathrm{ChB}, \mathrm{MD}$ \\ 1 Department of TeleHealth, Nelson R Mandela School of Medicine, University of KwaZulu-Natal, Durban, South Africa \\ ${ }^{2}$ NT Consulting - Global e-Health Inc., Calgary, Canada; Department of Community Health Sciences, Faculty of Medicine, University of Calgary, Canada
}

Corresponding author: M Mars (mars@ukzn.ac.za)

\begin{abstract}
Telemedicine has the potential to assist in the provision of healthcare in South Africa (SA). This means of healthcare service provision involves patients, doctors and machines working together, with few constraints imposed by geography, or national or institutional boundaries. Although the practice is largely beneficial, certain legal and ethical challenges arise from the use of electronic healthcare services. Certain ethical challenges are identified as: the changing nature of the traditional doctor-patient relationship; standards of care; quality of care; privacy; confidentiality; data protection; accountability; liability; consent; record-keeping; data storage; and authentication. While various legal, regulatory and governance measures offer potential solutions and remedies for protection, ethical direction may be achieved through statutory bodies set up to promote and foster ethical compliance with normative healthcare standards. Recently, the Health Professions Council of SA (HPCSA) made an attempt to address the ethical issues by publishing a set of telemedicine guidelines. Despite this, issues around the practice of telemedicine remain unresolved. This article seeks to inform the development of a new ethical framework by addressing three distinct and relevant ethical issues: the fiduciary nature of healthcare and the changing nature of the doctor-patient relationship; privacy, confidentiality and the sensitivity of health data; and informed consent. It does so by proposing a broader and more nuanced solution to these ethical obstacles by identifying conceptual and operational difficulties within the existing HPCSA telemedicine guidelines, and advancing suggestions for reform. This speaks to a more highly integrated perspective that is culturally and contextually aware, and which affirms the need to strike a balance between individual rights protection and transformative, ethical, healthcare innovation.
\end{abstract}

S Afr J Bioethics Law 2019;12(1):19-26. DOI:10.7196/SAJBL.2019.v12i1.662

While telemedicine holds enormous promise for the provision of remote healthcare, it is not without its challenges. Recently, there has been a shift in the way in which healthcare is being practised globally. These new models of healthcare service provision ideally involve patients, doctors and machines working together, with few constraints imposed by geography, or national or institutional boundaries. The World Health Organization (WHO) defines eHealth simply as 'the use of information and communication technologies [ICT] for health'; ; ${ }^{[1]}$ telemedicine, as a subset of eHealth, is the practice and delivery of healthcare over a distance using ICT. ${ }^{[2]}$

The focus of this article is telemedicine. However, the term eHealth will be applied when speaking of the use of ICT in healthcare generally, and telehealth where this term is applied by others, or when a slightly more generic perspective (one that includes telemedicine) is required.

Although largely beneficial, there is growing reflection on the legal and ethical challenges and complexities posed by these newly unfolding eHealth measures. ${ }^{[3,4]}$

There is a need for guidance with regard to the eHealth landscape in South Africa (SA). It is understood that the emergence of telemedicine has created various legal and ethical dilemmas. ${ }^{[5,6]}$ The broad ethical challenges are identified as: the changing nature of the traditional doctor-patient relationship; standards of care; quality of care; privacy; confidentiality; data protection; accountability; liability; consent; record-keeping; data storage; and authentication.

While various legal, regulatory, and governance measures offer potential solutions and remedies for rights protection, the furtherance of ethical direction may be achieved through statutory bodies set up to promote and foster ethical compliance with normative healthcare standards.

In SA, the Health Professions Council (HPCSA) spent several years developing the 'General ethical guidelines for good practice in telemedicine' (the HPCSA telemedicine guidelines), ${ }_{1}^{[7]}$ a process which they found difficult. ${ }^{[8]}$ Advances in technology and telemedicine have rendered several aspects of these guidelines, which focus largely on videoconference-based telemedicine, inappropriate. The guidelines are largely based on the World Medical Association (WMA)'s 2007 'Statement on the ethics of telemedicine', which was rescinded in 2009, and replaced with a far more pragmatic statement on 'Guiding principles for the use of telehealth for the provision of healthcare', which took recent advances in the field into account. ${ }^{[9]}$ The field has since advanced further, with the growing use of mobile phones for telemedicine. The current shortcomings of the HPCSA guidelines need to be addressed if telemedicine is to meet the government's desire for telemedicine to improve both access to and quality of care for those in rural areas. 
This article seeks to inform the development of any new ethical framework by addressing three distinct and relevant ethical issues: the fiduciary nature of healthcare and the changing nature of the doctor-patient relationship; privacy, confidentiality and the sensitivity of health data; and the need for informed consent for various aspects of telemedicine. It does so by providing a broader and more nuanced perspective on these ethical obstacles, by identifying conceptual and operational difficulties within the existing HPCSA telemedicine guidelines, and advancing suggestions for reform. This speaks to a more highly integrated perspective, one that is culturally and contextually aware, and which affirms the need to strike a balance between individual rights protection and transformative ethical healthcare innovation.

The intention is not to tackle all the complexities inherent in the discourse on telemedicine regulation and governance, nor to review all the traditional legal measures, be they legislative or otherwise. Moreover, it is not our intention to recommend specific solutions, since the current breadth and depth of awareness is low, and insufficient debate and discussion has yet taken place. Rather, our intent is to raise awareness, open debate and encourage understanding around means of telemedicine implementation in SA that are both pragmatic and achievable.

\section{Addressing challenges}

Telemedicine exposes both important advancements and shortcomings in traditional medicolegal and ethical discourse. ${ }^{[10]}$ For such initiatives to become sustainable and reach their potential, the industry requires clarification of the legal and ethical parameters within which it can operate successfully. ${ }^{[1]}$ As telemedicine applications create unique challenges, at issue is how they can best serve the interests of society in a meaningful and safe way, and what ethical parameters need to be established to assist this process. ${ }^{[12]}$ These parameters require regular review and refinement by focusing on the operational practices most likely to preserve the ethical practice of telemedicine.

The provision of healthcare in SA today faces numerous challenges, including a shortage of healthcare resources, an increased burden of disease, a large proportion of the population living in rural areas and gaps in both education and primary healthcare. ${ }^{[13,14]}$ Illness and death in developing countries are often due to health conditions that are preventable and for which medical solutions are known and easily implementable. ${ }^{[8,15]}$ Although still in its infancy in developing countries, the broader concept of eHealth holds the potential to transform healthcare, particularly for remote and vulnerable population groups. ${ }^{[11,16]}$ Certainly, some improvement in the accessibility, affordability and quality of care in the remotest areas is noteworthy, as eHealth seeks to offer and advance much-needed advice, diagnosis, treatment, second opinions and the prevention of disease. ${ }^{[17,18]}$ In this context telemedicine has gained considerable attention with many countries, including $\mathrm{SA}$, integrating it within their healthcare strategies. ${ }^{[19,20]}$

\section{Balancing ethics and innovation}

With the recognition that society is beginning to accept telemedicine, certain ethical issues have been noted ${ }^{[21]}$ Ethical issues in telemedicine were first identified in the early 1980s. In 2006, the WHO assigned the American Society for Bioethics and Humanities the task of identifying ethical issues in telemedicine. Their goal was to improve the quality of healthcare through the identification, analysis and resolution of certain ethical questions, and to promote practices consistent with ethical norms and standards, by advising institutional efforts in telemedicine policy development. ${ }^{[21-23]}$

As the law often lags behind technological development, an enhancement and realignment of normative frameworks may be required to address certain ethical gaps. ${ }^{[3]}$ The question is how, and to what extent, we identify the boundaries between viable solutions and futility that may be blurred by technology? We should not ask merely whether telemedicine ought to be regulated, but rather how 'health' is currently regulated, whether there is a level playing field and how such regulation should be more informed, effective, integrated and anticipatory. What is apparent is that with greater technological input, certain shifting notions in digital ethics, and their resultant implications in medical and telemedicine ethics, are creating new concerns. ${ }^{[24]} \mathrm{How}$ are these concerns to be reconciled in a meaningful, feasible and sustainable way that will both anticipate and steer the ethical development of technological innovation?

\section{The relationship between ethics, law and governance}

The use of ICT in healthcare raises various legal, ethical and governance difficulties. ${ }^{[3]} \mathrm{A}$ combination of eHealth-related governance, regulation and ethics in the form of laws, policies, regulations and guidelines may assist in filling these gaps and shaping the telemedicine landscape. This new framework, yet to be developed, will have to play out in a borderless, global, digital reality with numerous jurisdictions and issues of legal sovereignty. For this reason, it is prudent to consider a co-ordinated, co-operative and multi-layered approach to regulatory intervention and governance. This suggests the need for a solution predicated on a combination of both ethics and law, that is, state protection in the form of legally enforceable formal policy protection measures, together with a range of eHealth-specific guidelines and codes of conduct.

When considering ethics in the context of telemedicine, it is worth bearing in mind that an ethical dilemma is 'a choice which has to be made and one which is not covered by a law! ${ }^{[25]}$ Ethical guidance should therefore focus on issues where legislation does not yet exist or legislation is incomplete or remains ambiguous, or on subject matters that are outside the scope of legislation. ${ }^{[25]} \mathrm{New}$ guidelines should seek to dispel any ambiguities or inconsistencies in what is permitted, and should address only those lacunae that are not adequately addressed by other legal provisions. This would entail a process of delicately balancing, in a meaningful way, what is legally required against what is ethically desired, while simultaneously recognising the need for protection against any inadvertent drawbacks or damage from rapidly advancing technological development. All of this must be done through the lens of the specific contextual and nuanced milieu that is healthcare regulation in a modern, networked world.

\section{Who should inform the telemedicine ethical debate in SA?}

In an endeavour to offer ethical support to telemedicine, statutory bodies such as the HPCSA may be perfectly positioned to provide solutions within the national eHealth setting. Certainly, ethical challenges emerging in the formulations of ethical prerogatives and 
instruments intended to vindicate certain rights represent a rich source of opportunity. When advocating a solution, however, caution should be exercised against the implementation of guidelines that are intended to have an operational effect, but which are couched in the language of vague, granular control, enforce a one-size-fitsall approach and contain constructs that are both unilluminating, impracticable to implement and out of line with current everyday practice.

In proposing an ethical solution, it is suggested that any telemedicine guidance must: (i) be sensitive to societal and cultural differences in what is considered appropriate and realistic; (ii) be responsive, proactive and flexible to the rapid technological transformation in the healthcare industry; (iii) foster and build user confidence in adequate protection measures in this context; and (iv) align with clinical guidelines relevant to the specialty. This will encourage and enable eHealth implementation in $\mathrm{SA}$, and facilitate much-needed patient trust.

\section{The development of the HPCSA telemedicine guidelines}

The HPCSA is a statutory body, created pursuant to powers granted in terms of the Health Professions Act No. 56 of 1974. It is mandated to regulate and guide the healthcare professions in SA in aspects pertaining to the ethical beliefs and conduct of health professionals, and in 'fostering compliance with healthcare standards'. Significantly, this responsibility extends to both state and privately owned healthcare institutions. The council's role is twofold: firstly, to protect patients against possible abuse and secondly, to safeguard and provide guidance to healthcare practitioners. ${ }^{[26]}$ The SA eHealth strategy aims to improve access, service delivery and quality of care for rural communities in SA through telemedicine ${ }_{1}^{[19]}$ and to assist in the ethical practice of telemedicine in SA. To this end, the HPCSA recently published their telemedicine guidelines ${ }^{[7]}$ Certain conceptual and operational difficulties with these guidelines have since been identified. Although by no means exhaustive, the following concerns have been identified as requiring closer consideration.

\section{eHealth and telemedicine}

eHealth is a broad and multi-faceted concept, of which telemedicine is perhaps the most well-known element. The HPCSA's telemedicine guidelines only pertain to telemedicine as they have defined it (in a narrow sense), with an anticipation of, but limited guidance on, the role of direct patient-to-health-practitioner encounters in the eHealth process ${ }^{[7]} \mathrm{A}$ healthcare practitioner is defined in paragraph 3.3 as 'a person providing health services, registered in terms of the Health Professions Act No. 56 of 1974, to include any other appropriate disciplines as defined in the National Health Act No. 61 of 2003! ${ }^{[7]}$ It should be borne in mind that the HPCSA's guidelines relate only to those practitioners who are obliged to register with the HPCSA. It is therefore beyond the jurisdiction of the HPCSA to provide guidance to nurses, for instance, who would seek direction from the SA Nursing Council.

The definition of telemedicine in paragraph 3.1 provides for instances only between 'a healthcare practitioner in one location and a healthcare practitioner in another location'. While patient-initiated consultations are contemplated in paragraph 3.6, the extension to interactions between patients and healthcare practitioners, and the basis upon which these may be sought, is not clear and only applies where there is already an existing relationship between the patient and the healthcare practitioner. The position regarding other modalities, beyond physical consultations and 'face-to-face' interviews or examinations, using for instance, videoconferencing, various social media platforms or cellular applications such as WhatsApp, remains uncertain.

Insofar as the HPCSA's mandate is concerned, a duty exists to protect patients and provide guidelines for ethical healthcare provision within $\mathrm{SA}$, yet a whole spectrum of eHealth services is unaccounted for, and no direction given as to their ethical implementation. There are a plethora of eHealth activities and initiatives other than 'traditional' telemedicine interactions that are neither carefully described nor included within the ambit of the guideline definitions, and which require protection, yet the guidelines are crafted specifically for their defined vision of telemedicine, and nothing else.

A distinction is generally made between eHealth, telehealth and telemedicine, which has not been made in these guidelines. Whereas telemedicine has a healthcare practitioner as at least one of the participants, and is usually between one medical professional and another, eHealth and telehealth span a vast array of activities, with differing degrees of healthcare-practitioner involvement. All, however, involve use of ICT for healthcare purposes. ${ }^{[1,27]}$ The three components that these terms should reference are: $(i)$ the provision of all healthcare services, including telemedicine (ii) over physically separate environments (iii) using ICT.

Lastly, a question that may well require future consideration is whether there is a need for additional ethical guidelines embracing the broader eHealth landscape, that is, one which addresses a larger spectrum of eHealth-facilitated services. What is clear is that as certain constructs of healthcare practice change with the introduction of technology, medical practitioners practising telemedicine need to know what principles, values and standards they are to be held to, and the HPCSA should provide specific guidance in this regard. Additionally, appropriate guidance creates stability and certainty, which, in turn, can better sustain and support innovation.

\section{Maintaining standards of care and the doctor- patient relationship}

Any new iteration of the guidelines should reinforce the idea that the emergence of new technologies and new models of care do not alter a healthcare practitioner's fundamental ethical, professional and legal responsibilities around the provision of appropriate healthcare. While it is understood that the traditional doctor-patient relationship is evolving, this should not negate a health practitioner's primary duty of care, nor of maintaining high standards. It is critical that standards of care be non-negotiable and that basic, well-documented principles of the ethics that are applied in clinical practice should be carried through into eHealth settings.

Health practitioners are taught the importance of establishing a doctor-patient relationship as a basis for fostering mutual trust and empathy with their patients. One of the premises of this relationship is the therapeutic value of face-to-face encounters. This is reflected in the HPCSA's telemedicine guidelines, and is a point of contention in a remote, digitalised context. The guidelines refer to an 'actual face-toface consultation and physical examination of the patient' in paragraph 1.3. The 'consulting practitioner' will then communicate the information 
to the 'servicing practitioner. ${ }^{[7]}$ This suggests that the referring health practitioner should have undertaken a physical examination and thus have established the doctor-patient relationship. A pragmatic solution is the development of a video-conference 'face-to-face' consultation as the foundation of a doctor-patient relationship. ${ }^{[28]}$ Indeed, in the USA, all states now allow a physician to establish a relationship with a new patient via video-conference telemedicine. ${ }^{[28]}$ Furthermore, the American Medical Association (AMA), which has defined several ways in which a patient-physician relationship can be established for telemedicine, recognises video-conference examinations. ${ }^{[28]}$ In contrast, however, in store-and-forward telemedicine it is unlikely that the doctor to whom the case is referred will ever see or speak to the patient, yet this is the most cost-effective and efficient form of telemedicine for SA.

Conducting consultations remotely poses a significant ethical challenge in telemedicine. Despite the presumptive value of a physical consultation, the fundamental concept underlying telemedicine is to improve access to care from a distance, with the understanding that this replaces face-to-face encounters. As society becomes more comfortable with digital communication, it is envisaged that healthcare practices should align and evolve in this regard. Nevertheless, it is important to practically address apprehensions around the loss of the doctor-patient relationship, and to favour the adoption of modalities that can improve access to care in a safe manner. ${ }^{\left[{ }^{5,29]}\right.}$ Conversely, this may all be a 'storm in a tea cup': recent research concluded that ' $[t]$ he findings suggest that worries about the negative impact of web-based video consultation on the quality of patient-provider consultations seem unwarranted, as they offer the same interaction quality and satisfaction level as regular face-to-face consultations. ${ }^{\text {[30] }}$

As technology and telemedicine practice evolve, in some situations the requirement for a physical examination is transferred to the patient. Patients are being asked to submit self-taken photographs of their skin to a dermatologist for melanoma surveillance, or postoperative photographs of their wounds for assessment by their surgeon. ${ }^{[31]}$ This is an example of lacunae in the guidelines, which can be adequately and more relevantly addressed by discipline-specific clinical guidelines developed by the relevant specialties.

Worthy of consideration too is establishing and clarifying the duty of care in telemedicine encounters, and the ongoing responsibility of the patient, as well as the roles and responsibilities of any other healthcare professionals involved. Paragraph 4.3.2(a) of the HPCSA telemedicine guidelines states that responsibility resides with the referring doctor, based on the WMA 2007 statement. The $W_{M A}{ }^{[9]} 2009$ statement is more pragmatic, and takes into account differing circumstances: 'The physician needs to give clear and explicit direction to the patient during the telehealth encounter as to who has ongoing responsibility for any required follow-up and ongoing healthcare.' This is particularly important as the nature of a telemedicine encounter is one in which care of a patient often involves a team of healthcare professionals, and may even involve individuals not trained in healthcare (e.g. a family member, priest, counsellor, cancer survivor).

In addition to the need to follow standard clinical guidelines, there is a need for additional telemedicine guidelines, which should be developed by a relevant professional society or association. This is in accordance with advice given by the WMA and the AMA. However, a body such as the HPCSA cannot and should not be allowed to develop clinical guidelines for the practice of telemedicine in specialties as disparate, for example, as tele-echocardiology or telepsychiatry, nor for the encompassing field of eHealth.

\section{Privacy and confidentiality}

Although the rhetoric of technology-based healthcare innovation holds promise, safeguarding privacy and protecting data is an issue plaguing its successful implementation. ${ }^{[6,32]}$ The idea of a privacyrights discourse is not unfamiliar or unorthodox within healthcare, yet against this background a few fundamental difficulties emerge within the eHealth arena. The defining feature of eHealth is the significant role played by data ${ }^{[4]} \mathrm{A}$ necessary consequence is the creation of medical records, digital images, video and audio files and copious data, the subject of which is often personal and highly sensitive ${ }^{[33]}$ By its nature, telemedicine presupposes that personal health data freely navigates, and is shared, across various digital networks within a largely borderless setting; this is integral to the success of eHealth delivery systems. With the proliferation of personal, digitised data and the emergence of new forms of data collection and storage and the extensive sharing and transference of sensitive medical data, the implicit threat of misuse of such data becomes immediately apparent. ${ }^{[34]}$ Data may be produced by eHealth records, online healthcare applications and platforms, healthcare-monitoring technologies (including wearable devices and home sensors), online forums and public tracking sources. ${ }^{[35,36]}$

Like human subjectivity, conceptions of privacy, confidentiality and dignity are culturally constructed and are malleable and emergent, undergoing a process of evolution as individuals within societies engage in practices of mutually constituting self-definition. Privacy is culturally and contextually construed, and different communities have different norms about the extent to which various activities and information may be discussed or disclosed. ${ }^{[37,38]}$ Yet the rise of social media is severely testing the notion of privacy.

Certainly, questions of privacy necessitate a multi-layered regulatory approach to address them adequately. A number of overlapping legal measures exist to safeguard data privacy in SA, which is in the favourable position of having several legal sources of privacy protection. These include the law of delict, under the right to privacy contained in the SA Constitution, ${ }^{[39]}$ and recent provisions contained in omnibus data protection legislation. ${ }^{[40,41]}$ These means of protection run concurrently within the legal system and, rather than existing independently, their convergence and mutual interaction can serve to strengthen any consequential privacy protection. The mutually advantageous interaction between these sources of protection within the SA legal system not only renders individuals' rights in cases of violation protected in terms of law, but also provides the infringed party with clearly actionable and enforceable remedies.

It is noteworthy that the European Union in its recent General Data Protection Regulation (EU) 2016/679 provides increased protection for personal data, as well as more stringent regulation of health applications and devices (under the Medical Devices Regulation (EU) 2017/745). ${ }^{[42]}$ In the current SA legislative position (most significantly, the Protection of Personal Information Act No. 4 of 2013 (the 'POPI Act)), data privacy and its protection within healthcare requires consideration, as existing ethical frameworks may be insufficient to make sense of the challenges raised by electronic data. 
With regard to patient privacy and data protection, healthcare practitioners will need to comply with, inter alia, the provisions of existing legislation and regulations, for instance, the POPI Act, the National Health Act No. 61 of 2003 and the Electronic Transactions Act No. 25 of 2002, as well as any HPCSA guidelines. The HPCSA has developed a set of ethical rules and guidelines regulating the good ethical practice of confidentiality and the protection of information. These are set out in booklet 5 'Confidentiality: Protecting and providing information', and also in booklet 10, 'General ethical guidelines for good practice in telemedicine ${ }^{[7,43]}$

The justification for confidentiality and privacy, and its vindication, is implicitly predicated on the reality of social constructions and policy guidance instruments. The authors suggest that these guidelines should be more closely aligned with the provisions stipulated in SA legislative law, particularly with regard to the manner and extent of, for instance, data collection, security, storage and transfer, within the national eHealth ecosystem. From an ethical perspective, the guidelines should consider any particular ethical gaps pertaining specifically to healthcare data, rather than merely reiterating general principles, and the already more traversed terrain of other traditional and legislative regulatory sources. It is suggested that privacy, trust and innovation need not be mutually exclusive, and that privacy may enhance innovation.

\section{Informed consent}

The notion of 'consent' is deeply embedded in healthcare tradition, ${ }^{[44]}$ although 'informed consent' is a more recent notion developed largely within Westernised medical, legal and ethical paradigms. ${ }^{[45,46]}$ Consent provides a mechanism for providing permission for a specific purpose. ${ }^{[33]}$ Consent underpins the ethical principles of respect for individual autonomy and self-determination, and its worth diminishes in instances where it is limited. ${ }^{[47-49]}$ To consent presupposes a level of knowledge of what one is consenting to, or being 'informed'. Put simply, informed consent requires 'disclosure of all necessary information that a reasonable person would use in making an informed decision, in a format that is readily understandable to the individual, and without coercion influencing the choice.! ${ }^{\text {[25] }}$

In SA, the principle of informed consent flows from the SA Constitution, the National Health Act No. 61 of 2003, the common law and the HPCSA guidelines. Sections 6, 7 and 8 of the National Health Act provide for consent and the participation in decisionmaking processes. In particular, section 7(1) prescribes that '[s]ubject to section 8 , a health service may not be provided to a user without the user's informed consent,' and section 8(1) that '[a] user has the right to participate in any decision affecting his or her personal health and treatment.'

With regard to informed consent, the HPCSA telemedicine guidelines provide in paragraph 4.6.2 that '[i]nformed consent for the use of telemedicine technologies must be obtained in writing.' The guidelines then proceed to detail how this should be obtained, in paragraph 4.6.3. ${ }^{[7]}$ HPCSA booklet 4, 'Seeking patients' informed consent: The ethical considerations', sets out the minimum requirements when seeking informed consent from patients. ${ }^{[50]}$ The methods of obtaining consent imposed by the HPCSA for telemedicine should be aligned with consent in standard medical practice in SA. However, in contravention of current legislation, few doctors and nurses in SA routinely gain informed consent in face- to-face clinical practice. ${ }^{[51,52]}$ Elsewhere, Braddock et al., reviewing 1057 physician-patient encounters, involving 59 primary care physicians and 65 general or orthopaedic surgeons in the USA, found that just $9 \%$ of the 2553 clinical decisions made during these encounters met the criteria for completely informed decisionmaking ${ }^{[53]}$ Telemedicine should not be burdened with unrealistic expectations, particularly where it is the medium of interaction, and not a mechanism for delivery of treatment (e.g. teleconsultation v. telesurgery). Furthermore, it should be remembered that using a telephone to refer or discuss a patient with a colleague falls within the definition of telemedicine, and has been practised - without 'consent' - since the telephone was invented. Despite this reality, since it is 'the use of ICT for health', the HPCSA guidelines now require written informed consent, which must be witnessed, with a copy given to the patient for such a telephone consultation. ${ }^{[7]}$

Many of the questions pertaining to informed consent apply to all forms of medical practice - not just telemedicine - and demand further ethical consideration. But what constitutes 'informed' consent as an ethical tool within telemedicine development? If a 'full' understanding of what is being consented to is required, what then is reasonable and appropriate, in light of the fact that moral agency is exercised in the real world where a level of uncertainty is to be expected? Partial understanding, even with full and honest disclosure, may be inevitable despite every honest attempt at achieving a thorough understanding of what is being consented to. The social and cultural milieu creates an additional layer of complexity through which to traverse in making intricate and imperfectly informed decisions about future telemedicine activities.

With regard to telemedicine initiatives, the principle of consent potentially provides for two separate and distinct permissions: consent to (i) the medical treatment; and (ii) the use of technology. However, it is necessary to consider the implications of such mandatory consent for all telemedicine undertakings and, importantly, how this compares to current non-telemedicine mediated clinical practice. ${ }^{[51,53]}$

Informed consent turns on disclosing a full description of the therapy procedures, the risks and benefits, available alternatives and any relevant facts pertaining to the therapeutic treatment. ${ }^{[5,55]}$ Informed consent and the types of 'material risks' that have to be disclosed are to be found in SA common law and the National Health Act No. 61 of 2003. Both these law sources emphasise the need for patients to understand and appreciate the consequences of procedures, while the Act states in section 6(2) that patients must be given information at a level and in a language that they understand. Healthcare practitioners currently have then an obligation to share relevant information with their patient, and make a full and honest attempt at establishing understanding of what is being consented to, before the commencement of any telemedicine interaction. This information includes informing the patient of the objective of the telemedicine interaction, the role and responsibility of the provider and the patient during the telemedicine interaction, other people participating in the interaction, care documentation requirements, risks and benefits, and that the patient has the choice to decline to participate in the telemedicine interaction. ${ }^{[56]}$

In rethinking the concept of consent and its application, certain questions arise. Worth asking is whether, in a pluralistic society such as $\mathrm{SA}$, considering the impact of language and culture on telemedicine initiatives, together with the use of complex technological terminology, 
the notion of informed consent can be adequately addressed. ${ }^{[57,58]}$ Significant considerations are, for instance, in what language consent should be obtained, whether the lexicons of African languages have the necessary words to adequately communicate telemedicine concepts and whether the doctor, patient or translator have sufficient technology knowledge and understanding to adequately explain and answer patients' questions. Also worth asking is whether the patient can adequately understand the concepts of synchronous telemedicine, store-and-forward telemedicine, the internet and the world wide web in order to understand issues around transmission of data, among other things. All of this is required to allow a patient to be properly and meaningfully informed, and to fully appreciate that to which they are consenting.

Central to the enquiry regarding consent are the following issues: firstly, the nature and scope of the consent, the purpose for which it is being sought and the form in which such consent should be obtained. Is 'implied' or 'tacit' consent acceptable, and what then constitutes 'explicit' or 'express' consent? Should consent be 'specific', 'informed' and 'in writing'? Can 'consent' be obtained using a range of valid consent models that exist on a continuum from the very stringent to the more lenient? Can consent be 'bundled', and is 'blanket' consent acceptable, where consent is generally given for a vast range of activities? Additionally, what of 'forced consent', that is, where patients are coerced into accepting intrusive terms of service or else risk being denied access to treatment or services? And lastly, how can consent be obtained through electronic processes - and are data messages, e-consent and electronic transactions valid methods of obtaining consent? ${ }^{[59,60]}$

Secondly, in communities with significant rates of illiteracy, what alternatives can be found to guarantee effective consent? Can valid consent be obtained in such a way that unnecessary barriers to telemedicine provision are avoided? The imposition of written informed consent by regulators, particularly in countries with low literacy levels and significant language diversity, acts as an impediment to telemedicine use rather than an enabling factor. ${ }^{[15,57]}$

Thirdly, the notion of what constitutes valid, meaningful informed consent requires a nuanced approach. A failure to appreciate or integrate the specific notion of consent within the rich tradition and contextual philosophy of the local landscape, by simply transposing and adopting regulatory approaches appropriate elsewhere in the world, may be unsuitable and impractical. Increasingly in modern societies, topics of ethical contention often transcend an understanding of generally accepted norms and values, and should be shaped by greater considerations of local cultural and contextual sensitivity. ${ }^{[61]}$ SA courts have held that cultural practices must, however, be consistent with the SA Constitution and its emphasis on respect for human dignity and individual autonomy. ${ }^{[2-64]}$

While paradigms exist that turn on obtaining permissions, through various notice and consent models, a clear, robust, practical policy structure is required for these models to be operationally meaningful. Pragmatic considerations should influence the implementation of standards of consent, bearing in mind that consent is the pivotal issue around which the justification for the infringement of the individual's rights hinges. On the one hand, the danger in accepting a more limited version of consent is the inherent risk in offering justifications that are less than convincing, resulting in standards that are less than desirable. On the other hand, insisting on the implementation of impossibly high standards, in the full knowledge that practice and standards diverge, is to acknowledge that valid consent, in any event, is not being properly or sufficiently obtained. ${ }^{[52]}$ Although high expectations and standards are needed, what is required in practical terms is a way of reliably acceding to that bar. Ultimately, rules, techniques and methods regarding consent should describe a process of explanations and achievements, presenting an awareness of a reality that reflects imperfections and incompatibilities. Certainly, traditional consent-based approaches, when applied to an online healthcare environment within the context of a developing country, may not be desirably or easily implemented. Ideally, a consent model that addresses contextual and empirical issues is therefore needed, where it is understood that consent givers are subject to a variety of specific situational influences. ${ }^{[65]}$

\section{The way forward for SA}

The primary purpose of establishing telemedicine and privacy rights is to protect individual subjects. This approach places the individual, and individualised control, at the very heart of the discourse. Adopting an individual, or patient-centred, perspective speaks to respect for autonomy and the necessity to design operational practices in the form of approaches and policy conventions to effectively safeguard these rights. ${ }^{[12]}$

What should be encouraged is the confirmation and adoption of the helpful aspects already developed, and building on those valuable elements. Where concepts and measures are inappropriate, or where a range of choices exists, it is necessary to craft an appropriate, more comfortable position reflective of a developing telemedicine landscape. Expectations of performance and standards need not be lower but may simply be different, depending on the context. The passive adherence by the HPCSA to policies implemented in other parts of the world should not automatically be indicated for SA, where they may be inappropriate or imprecise. Rather, recommendations ought to be subjected to constant local scrutiny, debate, evolution and re-evaluation. Despite this, global common principles should lead to local complementary policy that would encourage, facilitate and support interjurisdictional telemedicine policy and practice in a 'glocal' way.

\section{Conclusion}

There have been considerable research efforts in recent years to create a common repository of reusable telemedicine system designs, documents, tools and codes, focusing primarily on the standards related to the technical interoperability of healthcare systems. This has allowed health information systems that are currently in operation to function as a viable whole. Despite this, little has been done to create a common cohesive repository of international telemedicine best practice, regulatory or ethical guidelines, protocols and/or legislation, which could be useful in the governance of data protection, particularly within the field of telemedicine in developing regions.

Organisations such as the HPCSA are perfectly positioned to embrace the challenges imposed by new healthcare technology, and to proactively provide insightful solutions in their guidelines. These guidelines, intended for operational application, should not be ineffective in practice. In addition to more general ethical guidelines, it is proposed that clinical, operational and ethical guidelines be developed by the governing bodies or associations of 
the various individual clinical disciplines using ICT in the provision of healthcare.

Despite navigating new and difficult terrain, sadly, the HPCSA guidelines in their current iteration do not provide a complete or satisfactory solution. We now have an opportunity to rectify this. There is hopefully sufficient motivation to devise more effective and realistic telemedicine regulations, and to implement them more rigorously.

\section{Acknowledgements. None.}

Author contributions. Equal contributions.

Funding. The research reported in this article was supported by the Fogarty International Center of the National Institutes of Health under award no. D43Tw007004.

\section{Conflicts of interest. None.}

1. World Health Organization. eHealth at WHO. http://www.who.int/ehealth/about/ en/ (accessed 1 June 2018).

2. Scott RE, Mars M. Telehealth in the developing world: Current status and future prospects. Smart Homecare Technol TeleHealth 2015;3:25-37. https://doi. org/10.2147/SHTT.S75184

3. Whitehouse D, George C, Duquenoy P. eHealth: Legal, ethical and governance challenges - an overview. In: Jordanova M, Lievens F, eds. Global Telemedicine and eHealth Updates: Knowledge Resources. Grimbergen: International Society for Telemedicine \& eHealth, 2011;4:423-428.

4. Vayena E, Haeusermann T, Adjekum A, Blasimme A. Digital health: Meeting the ethical and policy challenges. Swiss Med Wkly 2018;148:w14571. https://doi. org/10.4414/smw.2018.14571

5. Mehta SJ. Telemedicine's potential ethical pitfalls. Virtual Mentor 2014;16(12):10141017. https://doi.org/10.1001/virtualmentor.2014.16.12.msoc1-1412

6. Erwell CR. Telemedicine: Overcoming obstacles on the road to global healthcare Currents Int Trade Law J 2003;12:68.

7. Health Professions Council of South Africa. General ethical guidelines for good practice in telemedicine. Booklet 10. Pretoria: HPCSA, 2014. http://www.hpcsa. co.za/Uploads/editor/UserFiles/downloads/conduct_ethics/Booklet10.pdf (accessed 28 October 2018).

8. Kekana M, Noe P, Mkhize B. The practice of telemedicine and challenges to the regulatory authorities. S Afr J Bioethics Law 2010;3(1):33-37. http://www. sajbl.org.za/index.php/sajbl/article/view/92/70 (accessed 11 June 2019).

9. World Medical Association. Guiding principles for the use of telehealth for the provision of healthcare. Ferney-Voltaire: WMA, 2009. https://www.wma.net/ policies-post/wma-statement-on-guiding-principles-for-the-use-of-telehealthfor-the-provision-of-health-care/ (accessed 21 August 2018).

10. Harry B. Ethics and the interface between medicolegal and ethical issues. Curr Opin Psychiatry 1988;1(6):705-710.

11. Kiberu VM, Mars M, Scott RE. Barriers and opportunities to implementation of sustainable e-Health programmes in Uganda: A literature review. Afr J Prim Health Care Fam Med 2017;9(1):1-10. https://doi.org/10.4102/phcfm. v9i1.1277

12. Miesperä A, Ahonen SM, Reponen J. Ethical aspects of eHealth - systematic review of open access articles. Finnish J eHealth eWelfare 2013;5(4):165-171. https://doi.org/journal.fi/finjehew/article/view/9401

13. World Health Organization. World Health Statistics 2018: Monitoring health for the SDGs. Geneva: WHO, 2018. https://www.who.int/iris/handle/10665/272596 (accessed 26 October 2018).

14. Mars M, Seebregts C. Country case study for eHealth South Africa. Paper presented at: Making the eHealth Connection. Bellagio, Italy July 2008. https:// www.k4health.org/toolkits/hrh/country-case-study-e-health-south-africa (accessed 1 November 2018).

15. Le Roux A. Telemedicine: A South African legal perspective. J S Afr L 2008;1:99114.

16. Bergstrøm R, Heimly V. Information technology strategies for health and social care in Norway. Int J Circumpolar Health 2004;63(4):336-348. https://doi. org/10.3402/ijch.v63i4.17751

17. Marcolino MS, Oliveira JAQ, D'Agostino $M$, et al. The impact of mhealth interventions: systematic review of systematic reviews. JMIR Mhealth Uhealth 2018;6(1):e23. https://doi.org/10.2196/mhealth.8873

18. Commission of the European communities. $\operatorname{COM(2008)689}$ on Telemedicine for the benefit of patients, healthcare systems and society. Brussels: Commission of the European Communities, 2008. https://eur-lex.europa.eu/LexUriServ/ LexUriServ.do?uri=COM:2008:0689:FIN:EN:PDF (accessed 26 October 2018).
19. Department of Health, South Africa. National eHealth Strategy South Africa 2012 - 2016. Pretoria: DoH，2012. https://www.health-e.org.za/wp-content/ uploads/2014/08/South-Africa-eHealth-Strategy-2012-2017.pdf (accessed 11 June 2018).

20. World Health Organization. Telemedicine: Opportunities and developments in member states. Report on the second global survey on eHealth. Geneva:WHO, 2010.

21. Langarizadeh $\mathrm{M}$, Moghbeli $\mathrm{F}$, Aliabadi A. Application of ethics for providing telemedicine services and information technology. Med Arch 2017;71(5):351352. https://doi.org/10.5455/medarh.2017.71.351-355

22. Kon AA, Walter RJ. Healthcare ethics consultation via telemedicine: Linking expert clinical ethicists and local consultants. AMA J Ethics 2016;18(5):514-520. https://doi.org/10.1001/journalofethics.2016.18.5.stas1-1605

23. American Society for Bioethics and Humanities. Core Competencies for Healthcare Ethics Consultation. 2nd edition. Chicago: ASBH, 2011.

24. Floridi L. Soft ethics and the governance of the digital. Philos Technol 2018;31:1. https://doi.org/10.1007/s13347-018-0303-9

25. European Health Telematics Association. Ethical principles for eHealth - EHTEL briefing paper. Brussels: EHTEL, 2012. https://www.ehtel.eu/publications/ position-and-briefing-papers/ETHICAL-briefing-principles-for-ehealth/view (accessed 12 June 2018).

26. Health Professions Council of South Africa. Booklets 1 - 15. http://www.hpcsa. co.za/Conduct/Ethics (accessed 12 June 2018).

27. Kaplan B, Litewka, S. Ethical challenges of telemedicine and telehealth Camb Q Healthcare Ethics 2008;17(4):401-416. https://doi.org/10.1017/ S0963180108080535

28. Farouk A. Telemedicine prompts new ethical ground rules for physicians. American Medical Association, 2016. https://wire.ama-assn.org/ama-news/ telemedicine-prompts-new-ethical-ground-rules-physicians (accessed 6 July 2018).

29. Idan A, Wallach HS, Almagor M, Waisman Y, Linn S. Mediated telemedicine v. face-to-face medicine: Efficiency in distress reduction. J Multimodal User In 2015;9(4):333-339. https://doi.org/10.1007/s12193-015-0181-8

30. Tates K, Antheunis ML, Kanters S, Nieboer TE, Gerritse MB. The effect of screento-screen v. face-to-face consultation on doctor-patient communication: An experimental study with simulated patients. J Med Internet Res 2017;19(12):e421. https://doi.org/10.2196/jmir.8033

31. Mars M, Morris C, Scott RE. Selfie telemedicine: What are the legal and regulatory issues? Stud Health Technol Inform 2018;254:53-62. https://doi.org/10.3233/978 1-61499-914-0-53

32. Rainie L, Fox S. The online health care revolution. Pew Internet Organisation, 2000. http://www.pewinternet.org/2000/11/26/the-online-health-care-revolution/ (accessed 25 October 2018).

33. Nuffield Council on Bioethics. The collection, linking and use of data in biomedical research and health care: Ethical issues. http://nuffieldbioethics.org/wp-content/ uploads/Biological_and_health_data_web.pdf (accessed 5 June 2018).

34. Hohmann J, Benzschawel S. Data protection in eHealth platforms. In: Beran R, ed. Legal and Forensic Medicine. Berlin: Springer-Verlag, 2013:1633-1658. https:// doi.org/10.1007/978-3-642-32338-6_81

35. Costa FF. Big data in biomedicine. Drug Discov Today 2014;19(4):433-440. https:// doi.org/10.1016/j.drudis.2013.10.012

36. Lupton $D$. The commodification of patient opinion: The digital patient experience economy in the age of big data. Sociol Health Illn 2014;36(6):856-869. https://doi. org/10.1111/1467-9566.12109

37. Collste G. Global ICT-ethics: The case of privacy. J Inform Commun Ethics Society 2008;6 (1):76-87. https://doi.org/10.1108/14779960810866819

38. Kukathas C. Explaining moral variety. Soc Philos Policy 1994;11(1):1-21. https:// doi.org/10.1017/S026505250000426X

39. South Africa. Constitution of the Republic of South Africa, 1996. Section 10.

40. Roos A. Data protection. In: Van der Merwe DP, Roos A, Pistorius T, Eiselen S, eds. Information and Communications Technology Law. Durban: LexisNexis, 2008.

41. Papadopoulos S, Snail S. Privacy and data protection. In: Papadopoulos S, Snail S, eds. Cyberlaw @ SA III: The Law of the Internet in South Africa, 3rd edition. Pretoria: Van Schaik, 2012:275-314.

42. Lang M. Heart rate monitoring apps: Information for engineers and researchers about the new European medical devices regulation. JMIR Biomed Eng 2017;745(2)1:e2. https://doi.org/10.2196/biomedeng.8179

43. Health Professions Council of South Africa. Confidentiality: Protecting and providing information. Booklet 5. Pretoria: HPCSA. 2016. http://www.hpcsa.co.za/ Uploads/editor/UserFiles/downloads/conduct_ethics/Booklet5.pdf (accessed 28 October 2018).

44. Dalla-Vorgia P, Lascaratos J, Skiadas P, Garanis-Papadatos T. Is consent in medicine a concept only of modern times? J Med Ethics 2001;27(1):59-61. https://doi. org/10.1136/jme.27.1.59

45. Beauchanp TI, Faden RR. Informed consent: I. History of informed consent. In Post SG, ed. Encyclopedia of Bioethics. Michigan: Gale, 2004. 
46. Hall DE, Prochazka AV, Fink AS. Informed consent for clinical treatment. Can Med Assoc J 2012;184(5):533-540. https://doi.org/10.1503/cmaj.112120

47. Sørensen K, Schuh B, Stapleton G, Schröder-Bäck P. Exploring the ethical scope of health literacy: A critical literature review. Alban Med J 2013;2:71-83.

48. Organisation for Economic Co-operation and Development Guidelines on the Protection of Privacy and Transborder Flows of Personal Data. Paris: OECD 1980. http://www.oecd.org/internet/ieconomy/ oecdguidelinesontheprotectionofprivacyandtransborderflowsofpersonaldata.htm (accessed 26 October 2018).

49. Otlowski MFA. Tackling legal challenges posed by population biobanks: Reconceptualising consent requirements. Med Law Rev 2012;20(2)191-226. https:// doi.org/10.1093/medlaw/fwr035

50. Health Professions Council of South Africa. Seeking patients' informed consent: The ethical considerations. Booklet 4. Pretoria: HPCSA, 2016. http://www.hpcsa.co.za/ Uploads/editor/UserFiles/downloads/ethical rules/Booklet\%204\%20Informed\%20 Consent $\% 20$ September\%20\%202016.pdf (accessed 28 October 2018).

51. Jack C, Singh Y, Mars M. Pitfalls in computer housekeeping by doctors and nurses in KwaZulu-Natal: No malicious intent. BMC Med Ethics 2013;14(Suppl 1):S8. https:// doi.org/10.1186/1472-6939-14-S1-S8

52. Jack C, Mars M. Informed consent for telemedicine in South Africa: A survey of consent practices among healthcare professionals in Durban, KwaZulu-Natal. S Afr J Bioeth Law 2013;6(2):55-59. http://www.sajbl.org.za/index.php/sajbl/article/ view/287/315 (accessed 11 June 1019).

53. Braddock III CH, Edwards KA, Hasenberg NM, Laidley TL, Levinson W. Informed decision making in outpatient practice: Time to get back to basics. JAMA 1999;282(24):2313-2320. https://doi.org/10.1001/jama.282.24.2313

54. Martinez-Martin N, Kreitmair K. Ethical issues for direct-to-consumer digital psychotherapy apps: Addressing accountability, data protection and consent. JMIR Ment Health 2018;5(2):e32. https://doi.org/https://mental.jmir.org/2018/2/e32/

55. Silva GS, Schwamm LH. Use of telemedicine and other strategies to increase the number of patients that may be treated with intravenous thrombolysis. Curr Neuro Neurosci Rep 2012;12(1):10-16. https://doi.org/10.1007/s11910-011-0235-6
56. Kluge E-HW. Ethical and legal challenges for health telematics in a global world Telehealth and the technological imperative. Int J Med Inform 2011;80(2):e1-5. https://doi.org/10.1016/j.ijmedinf.2010.10.002

57. Jack C, Singh Y, Hlombe B, Mars M. Language, cultural brokerage and informed consent - will technological terms impede telemedicine use? S Afr J Bioeth Law 2014;7(1):14-18. http://doi.org/10.7196/sajbl.291. http://www.sajbl.org.za/index php/sajbl/article/view/309/334 (accessed 11 June 2019).

58. Pachter LM, Sheehan J, Cloutier MM. Factor and subscale structure of a parental health locus of control instrument for use in a mainland United States Puerto Rican community. Soc Sci Med 2000;50(5):715-721. https://doi.org/10.1016/S02779536(99)00323-8

59. United Nations Commission on International Trade Law (UNCITRAL). Model Law on Electronic Commerce. Geneva: UNCITRAL, 1996. http://www.uncitral.org/pdf/ english/texts/electcom/V1504118_Ebook.pdf (accessed 26 October 2018).

60. South Africa. Electronic Communications and Transactions Act No. 25 of 2002 Chapter III. Part I s 11(1) - (3), s 12, s 14(1) and (2), s 15(1) - (4), s 16 (1) and (2), s 17(1) and (2).

61. Molyneux CS, Peshu N, Marsh K. Trust and informed consent: Insights from community members on the Kenyan coast. Soc Sci Med 2005;61(7):1463-1473. https://doi.org/10.1016/j.socscimed.2004.11.073

62. Sv Makwanyane and another (CCT3/94) [1995] ZACC 3; 1995 (6) BCLR 665; 1995 (3) SA 391; [1996] 2 CHRLD 164; 1995 (2) SACR 1, at paras 310, 323, 365-366, 373.

63. Bhe and others v Khayelitsha Magistrate and others B 2005 (1) SA 580 (CC), at para 4

64. MEC for Education: KwaZulu-Natal and Others v Pillay (CCT 51/06) [2007] ZACC 21 2008 (1) SA 474 (CC); 2008 (2) BCLR 99 (CC), at paras 53, 54, 62, 142, 149-158.

65. Carolan E. The continuing problems with online consent under the EU's emerging data protection principles. Comput Law Secur Rev 2013;32(3):462-473. https://doi. org/10.1016/j.clsr.2016.02.004

Accepted 22 May 2019 